\title{
Correction to: Solution-Processed Insulators for Flexible Metal-Insulator-Metal Structures
}

\author{
AKSHITA MISHRA, ${ }^{1}$ SOUMEN SAHA,${ }^{1}$ CHANDAN KUMAR JHA, ${ }^{2}$ \\ VASUDHA AGRAWAL, ${ }^{1}$ BHASKAR MITRA,${ }^{1}$ ABHISEK DIXIT, ${ }^{2}$ \\ and MADHUSUDAN SINGH (D) ${ }^{1,3}$ \\ 1.-Functional Materials \& Devices Laboratory, Department of Electrical Engineering, IIT Delhi, \\ Hauz Khas, New Delhi 110 016, India. 2.-Wafer Level Characterization Laboratory, Department \\ of Electrical Engineering, IIT Delhi, Hauz Khas, New Delhi 110 016, India. 3.-e-mail: \\ msingh@ee.iitd.ac.in
}

\section{Correction to:}

Journal of ELECTRONIC MATERIALS,

Vol. 48, No. 5, 2019

https://doi.org/10.1007/s11664-019-06975-4

In the original article, there is an error in the legend in Fig. 4. Following is the corrected figure:

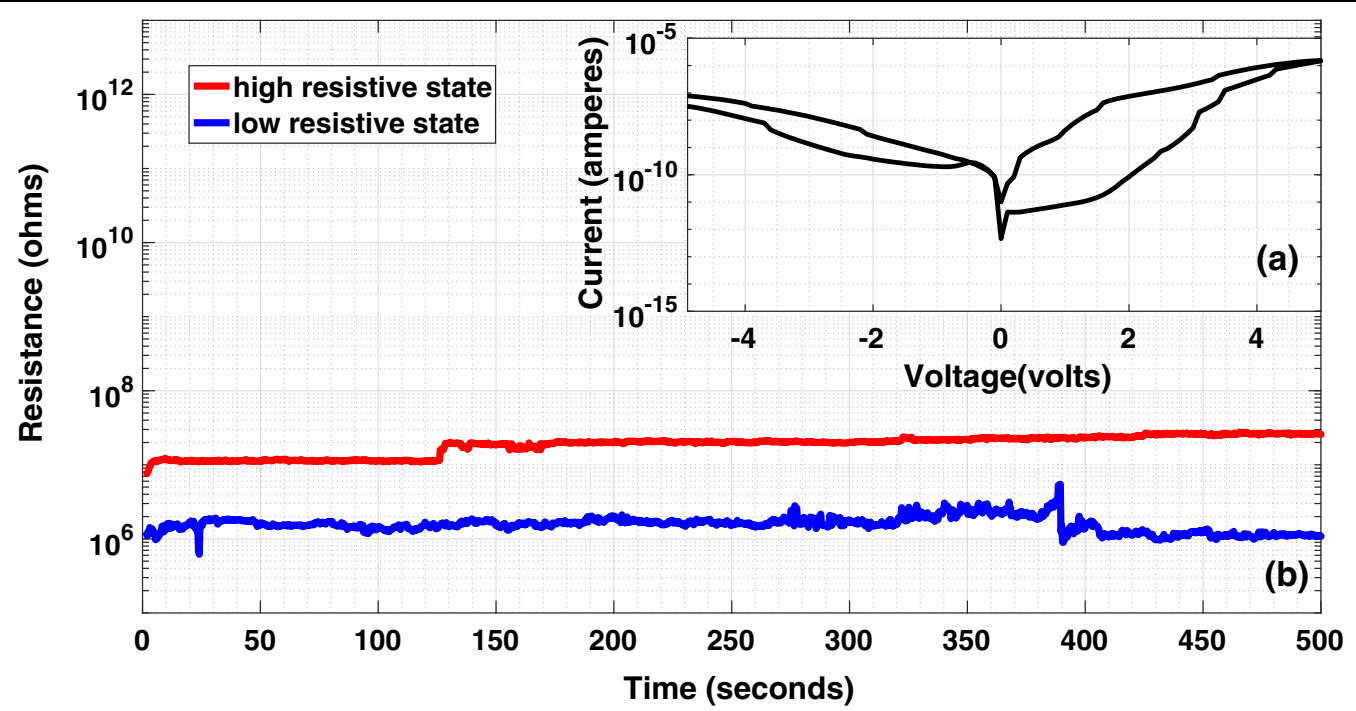

Fig. 4. Electrical characterization: (a) current-voltage characteristics of the device with Au and Ag contacts, (b) retention characteristics.

Publisher's Note Springer Nature remains neutral with regard to jurisdictional claims in published maps and institutional affiliations. 